\title{
Hydrocolloids retard lipid digestion in whipping cream
}

\author{
*Srikaeo, K. and Doungjan, S. \\ Faculty of Food and Agricultural Technology, Pibulsongkram Rajabhat University, Muang, Phitsanulok \\ 65000, Thailand
}

\begin{abstract}
Article history:
Received: 11 December 2019

Received in revised form: 22

January 2020

Accepted: 23 January 2020

Available Online: 15 January 2020
\end{abstract}

Keywords:

Whipping cream,

Whipped cream,

Carrageenan,

Pectin,

Lipid digestion,

Emulsion

DOI:

https://doi.org/10.26656/fr.2017.4(3).407

\begin{abstract}
This paper evaluated the effects of two hydrocolloids, pectin and carrageenan, on physical properties and lipid digestion of whipping cream. Hydrocolloids were added to the creams at $0.5,1.0$ and $1.5 \%$ by weight. Their physical properties and lipid digestion were examined. It was found that both pectin and carrageenan affected lipid droplet size and $\zeta$ potential of the emulsions, causing the volume-surface average diameter to decrease while the net negative charges of the lipid droplets increased. Hydrocolloids provided the key benefits to whipped creams as they improved foaming properties and delayed lipid digestion rate. Overrun and serum loss of the whipped creams were improved. Hydrocolloids reduced the rate of lipid digestion as evidenced by lipid droplet aggregations either by coalescence or flocculation mechanisms. The released free fatty acids which are the end products of lipid digestion were reduced as a consequence of hydrocolloid addition. The decrease of lipid digestion rate depended on the types and concentrations of hydrocolloids. Carrageenan was found to be more effective than pectin in terms of delaying lipid digestion.
\end{abstract}

\section{Introduction}

Whipped cream is a popular topping for desserts, cakes and pastries, as well as an ingredient in many dishes. It is an aerated emulsion which is formed through whipping dairy cream, an oil-in-water $(\mathrm{O} / \mathrm{W})$ emulsion with at least $35 \%$ fat content. In the whipping process, fat globules in cream were absorbed by serum protein and milk fat globule membrane fractions at the air/water interface (Dewettinck et al., 2008). These fat globules then form a partial crystal network cover air bubbles through a phenomenon called the surface-mediated partial coalescence (Hotrum et al., 2005; Nguyen et al., 2015).

Emulsion is an unstable system due to flocculation, creaming, coalescence, phase inversion and Ostwald ripening (Thanasukarn et al., 2004). Some food additives such as emulsifier, proteins or polysaccharides are usually used to improve the quality of dairy products. Emulsifiers play an important role in improving the stability of aerated food emulsions by absorption at the interface, thereby lowering the interfacial tension (Wollenweber et al., 2000). Proteins and polysaccharides are often applied in the emulsion as emulsifiers. Proteins are usually used for their surfactant and gelling properties to improve the textural characteristics and stability of the emulsion, while polysaccharides are usually added to increase the viscosity or to obtain a gellike product (Hemar et al., 2001; Pérez et al., 2007). The effect of emulsifiers depends on the type, blend and concentration. The best known and most well used of emulsifiers are that casein and carrageenan (Dalgleish and Morris, 1988). Recently, the effects of other polysaccharides or hydrocolloids on rheological and textural properties of whipped cream have been studied. These included locust bean gum (Camacho et al., 1998; 2001; 2005), hydroxypropyl methylcellulose (Zhao, Zhao, Li et al., 2009), xanthan gum (Zhao, Zhao, Yang et al., 2009), and various seed gums (Farahmandfar et al., 2017; Farahmandfar et al., 2019).

In recent years, the beneficial effects of a healthy diet on the quality of life, as well as on the costeffectiveness of health care, are widely recognized. The high amount of dietary fat is associated with increased risk of health hazards such as cardiovascular diseases, hypertension and obesity. These problems have prompted consumers to be more aware of high-fat diets. For this reason, there has been pressure on the food industry to develop food products with special healthenhancing characteristics (Farahmandfar et al., 2017). As mentioned earlier, various hydrocolloids have been exploited in whipped cream as texture improving agents. 
The basic property of hydrocolloids that lends them to be considered as a healthy food ingredient is that they are dietary fibers (Viebke et al., 2014). Therefore, these hydrocolloids may also affect the lipid digestion and retard lipolysis. It has been reported that hydrocolloids induced flocculation of lipid droplets in the gastrointestinal tract and consequently caused a decrease of the lipid digestion rate. The results depended on the type of hydrocolloids and simulated gastrointestinal tract model used for evaluation (Qin et al., 2017).

In view of the importance of hydrocolloids, not only as emulsion stabilizers but also functional dietary fibers that could retard lipid digestion rate, this study aimed to evaluate the effects of several hydrocolloids including carrageenan and pectin on physical properties and lipid digestion of whipping cream. Carrageenan is an anionic, high molecular weight sulfated GRAS polysaccharide, obtained from certain species of red seaweed. While pectin is a complex anionic polysaccharide composed of $\beta$-1, 4-linked D-galacturonic acid residues, where the uronic acid carboxyls are either fully (high-methoxy pectin) or partially (low-methoxy pectin) methyl esterified. The mentioned hydrocolloids are commonly used in the manufacturing of whipped cream. In addition, most previous studies about the use of hydrocolloids in whipped cream focused on rheological properties and not much information about lipid digestion, the information obtained from this study could add up the knowledge and help the industry to design proper whipped cream with better functional properties.

\section{Materials and methods}

\subsection{Materials}

Carrageenan (Satiagel ${ }^{\mathrm{TM}} \mathrm{ME} 5$, food grade) and pectin (Unipectine ${ }^{\mathrm{TM}}$, high-methoxyl food grade) were purchased from Cargill Inc. (Philippines). All the chemicals were analytical grade and purchased from Sigma-Aldrich (Thailand).

\subsection{Sample preparation}

The hydrocolloid solution was prepared by dispersing the hydrocolloid in distilled water and stirring with a magnetic stirrer at ambient temperature until full dissolution. The solutions were stored at $4^{\circ} \mathrm{C}$ overnight for complete hydration (Farahmandfar et al., 2017). Fresh cream with a fat content of approximately $30 \%$ was obtained from a local dairy factory. Fat content was adjusted by the addition of raw skimmed milk to $40 \%$ fat cream. Then, $0.5,1.0$ and $1.5 \%$ by weight of the hydrocolloid solutions were added to the cream. Samples were then pasteurized at $85^{\circ} \mathrm{C}$ for 5 mins in a water bath, homogenized at $50^{\circ} \mathrm{C}$ and 3,000 RPM for 1 min using Ultra Turex homogenizer (Ultra-Turrax ${ }^{\circledR}$ T18, IKA,
Germany). The treated creams were refrigerated for 24 hrs at $4^{\circ} \mathrm{C}$ to promote fat crystallization and support the formation of foam structure during whipping. After cooling, whipping cream was ready for aeration which was done using a stand mixer (Kenwood, Model KM 280, China). In addition, the cream after refrigeration was also used to examine for their in-vitro lipid digestion properties.

\subsection{Particle size and $\zeta$-potential measurements}

Particle size distribution of the emulsions after homogenization was measured by an integrated-laser light scattering instrument (Mastersizer 2000, Malvern Instruments Co. Ltd., Worcestershire, UK). Relative refractive index and absorption were set as 1.414 and 0.001 , respectively. The emulsion in the sample chamber was diluted 1000-fold with distilled water. The percentage of volume (\%) was recorded. The average particle size (volume-surface average diameter, $d_{3,2}$ ) was obtained from triplicate measurements.

The electrophoretic mobility expressed as $\zeta$-potential was determined using a Zetasizer Nano-ZS (Malvern Instruments, UK). The emulsion was diluted 1000-fold with distilled water to avoid multiple scattering effects before measurements. All the measurements were conducted in triplicate at $25^{\circ} \mathrm{C}$

\subsection{Foaming properties}

Foaming properties were evaluated based on overrun and serum loss. Overrun is $\mathrm{mL}$ of air per $100 \mathrm{~mL}$ of cream. It was measured by the method described earlier (Scurlock, 1986), by filling a tub to a set volume with the cream before and after whipping treatment. The overrun was related to the weight of this volume and the density of the cream before whipping. It was determined according to the following equation:

$\%$ Overrun $=\frac{(\text { Unwhipped cream }(g)-\text { Whipped cream }(g))}{\text { Whipped cream }(g)} \times 100$

Whipping was stopped when the foam reached maximum overrun, after which the weight of the sample began to increase because foam tends to collapse on continued whipping, leading to the formation of butter granules (Farahmandfar et al., 2017).

Serum loss was determined using the method described earlier (Nguyen et al., 2015) with some modifications. The foam $(20 \mathrm{~g})$ was filled in a glass filter which was put above a $100 \mathrm{~mL}$ Erlenmeyer flask. The amount of liquid $(\mathrm{mL})$, which separated from the foam by natural gravity collected in the flask, was recorded after $3 \mathrm{hrs}$. The serum loss was calculated according to the following equation: 
$\%$ Serum loss $=\frac{\text { Serwm collected }(g)}{\text { Initialwhipped cream }(g)} \times 100$

\subsection{Lipid digestion}

The in-vitro lipid digestion model used in this study was a modification of that described previously (Beysseriat et al., 2006; Klinkesorn and McClements, 2009). The model was designed to simulate the $\mathrm{pH}$ variations that food experiences during passage through the human digestive system. The procedure was as follows: emulsions were prepared as described above, adjusted to $\mathrm{pH} 7.0$ with $\mathrm{NaOH}$ (if necessary) and stored at $37^{\circ} \mathrm{C}$ for $1 \mathrm{hr}$. These emulsions were acidified to $\mathrm{pH}$ 2.0 with $\mathrm{HCl}$, then incubated at $37^{\circ} \mathrm{C}$ for $1 \mathrm{hr}$ in a shaking incubator $(95 \mathrm{rpm})$. The acidified emulsions were raised to $\mathrm{pH} 5.3$ with $\mathrm{NaOH}$, followed by the addition of the Lipex ${ }^{\circledR}$ lipase solution (Novozymes, Denmark) to give a final concentration of $0.05 \mathrm{mg} / \mathrm{mL}$ sample and incubated for $2 \mathrm{hrs}$ at $37^{\circ} \mathrm{C}$. Finally, the $\mathrm{pH}$ of the emulsion was increased to 7.5 with $\mathrm{NaOH}$ and the samples were incubated at $37^{\circ} \mathrm{C}$ for $2 \mathrm{hrs}$, shaking at 95 rpm, to complete the intestinal phase of the in-vitro digestion process.

Creaming stability was determined by measuring the percentage of the height of the cream layer formed at the top of the emulsion after $24 \mathrm{hrs}$ storage at $25^{\circ} \mathrm{C}$ (Srikaeo and Singchai, 2016).

The microstructure of the emulsions was determined via optical microscopy using a Nikon Eclipse E400 microscope (Nikon Corporation; Japan). A drop of sample from each stage of the digestion model was placed on a microscope slide, covered by a coverslip and observed at a magnification of $200 \mathrm{X}$.

The free fatty acids (FFAs) released after digestion was determined by titrimetry using $0.25 \mathrm{~N} \mathrm{NaOH}$ and phenolphthalein as an indicator to the endpoint (pink color). FFAs were expressed as oleic acid and calculated from a standard curve previously prepared using oleic acid as the reference (Mun et al., 2007; Srikaeo and Pradit, 2011).

\subsection{Statistical analysis}

All values are expressed as means \pm standard deviations from triplicated data. Statistical analysis of data was performed using one-way ANOVA. Mean comparison was carried out using Duncan's multiple range test. Differences were considered to be statistically significant when $\mathrm{p} \leq 0.05$.

\section{Results and discussion}

\subsection{Particle size and $\zeta$-potential measurements}

The particle size distribution as evaluated by volume -surface average diameter $\left(\mathrm{d}_{2,3}\right)$ and $\zeta$-potential values are shown in Table 1.

Table 1. Volume-surface average diameter $\left(\mathrm{d}_{2,3}\right)$ and $\zeta$ potential of the whipping cream emulsions

\begin{tabular}{lcc}
\hline Samples & $\begin{array}{c}\text { volume-surface } \\
\text { average diameter } \\
\left(\mathrm{d}_{2,3}\right)(\mu \mathrm{m})\end{array}$ & $\begin{array}{c}\zeta \text {-potential values } \\
(\mathrm{mV})\end{array}$ \\
\hline Control & $3.74 \pm 0.04^{\mathrm{a}}$ & $-8.44 \pm 0.45^{\mathrm{a}}$ \\
Carrageenan $0.5 \%$ & $2.25 \pm 0.06^{\mathrm{d}}$ & $-13.41 \pm 0.11^{\mathrm{b}}$ \\
Carrageenan 1.0\% & $2.15 \pm 0.06^{\mathrm{d}}$ & $-14.56 \pm 0.13^{\mathrm{c}}$ \\
Carrageenan 1.5\% & $1.50 \pm 0.01^{\mathrm{e}}$ & $-14.75 \pm 0.18^{\mathrm{c}}$ \\
Pectin 0.5\% & $2.88 \pm 0.03^{\mathrm{b}}$ & $-14.36 \pm 0.04^{\mathrm{c}}$ \\
Pectin 1.0\% & $2.81 \pm 0.02^{\mathrm{bc}}$ & $-15.70 \pm 0.04^{\mathrm{d}}$ \\
Pectin $1.5 \%$ & $2.65 \pm 0.06^{\mathrm{c}}$ & $-15.93 \pm 0.08^{\mathrm{d}}$ \\
\hline
\end{tabular}

Values are mean \pm standard deviation (triplicate). Means with different superscript letters within a column are significantly different $(\mathrm{p} \leq 0.05)$.

Volume weighted mean diameter and $\zeta$-potential are the important emulsifying properties. From Table 1, it was found that volume-surface average diameter of the hydrocolloid added samples were lower than that of the control. This indicated that both pectin and carrageenan enhanced the efficiency of homogenization causing the small emulsion droplets. Carrageenan added samples exhibited slightly lower diameter than pectin added samples. In terms of concentrations, the surfaceweighted mean diameters decreased gradually as the concentration of hydrocolloids increased. Both pectin and carrageenan exhibited similar behaviors. Previous studies have found that increasing concentration of several gums and sugar beet pectin decreased the emulsion droplets gradually until it reached a saturated surface coverage at where the diameter remained unchanged (Yao et al., 2016). Similar results were also reported in carrageenan (Chang and McClements, 2016).

In terms of electrophoretic ability, the $\zeta$-potential of emulsions increased as hydrocolloid concentrations increased. Both pectin and carrageenan are anionic polysaccharides and they adsorbed to the surface of the oil droplets contributed to the negative charges as evidenced by $\zeta$-potential values.

Oil droplet size and $\zeta$-potential also influence lipid digestion rate. Studies have found that the lipid digestion rate does increase with decreasing droplet size since this would lead to an increase in the surface area of lipid exposed to the lipase (Yao et al., 2016). However, the nature and thickness of the interfacial layer surrounding the lipid droplets also play an important role in determining the rate and extent of lipid hydrolysis (Torcello-Gómez et al., 2012). 


\subsection{Foaming properties}

The effects of carrageenan and pectin on overrun and serum loss of the whipped cream samples are shown in Figure 1.

From Figure 1, the overrun of whipped cream samples increased as the hydrocolloid level increased. The overrun of the control sample was $120 \%$ and then increased up to a maximum of $170 \%$ when added with hydrocolloids. Pectin generally exhibited higher overrun values than those of carrageenan. The concentration of both hydrocolloids did not significantly affect overrun values. Overrun is an indicator which gives information on the gas holdup or the percentage of gas in the whipped cream (Jakubczyk and Niranjan, 2006). Maximal overrun corresponds with the maximal stability and stiffness of the foam. The air bubbles are encapsulated by coalesced fat droplets which distribute well at the air/slurry interface. The emulsion with hydrocolloids could incorporate large quantities of air during whipping. Moderate hydrocolloid levels can give more opportunity for air incorporation. Once most of the air has been incorporated into the emulsion, the emulsion gives a strong combination and reinforces the stabilization of the already incorporated air cells (Allen et al., 2006).
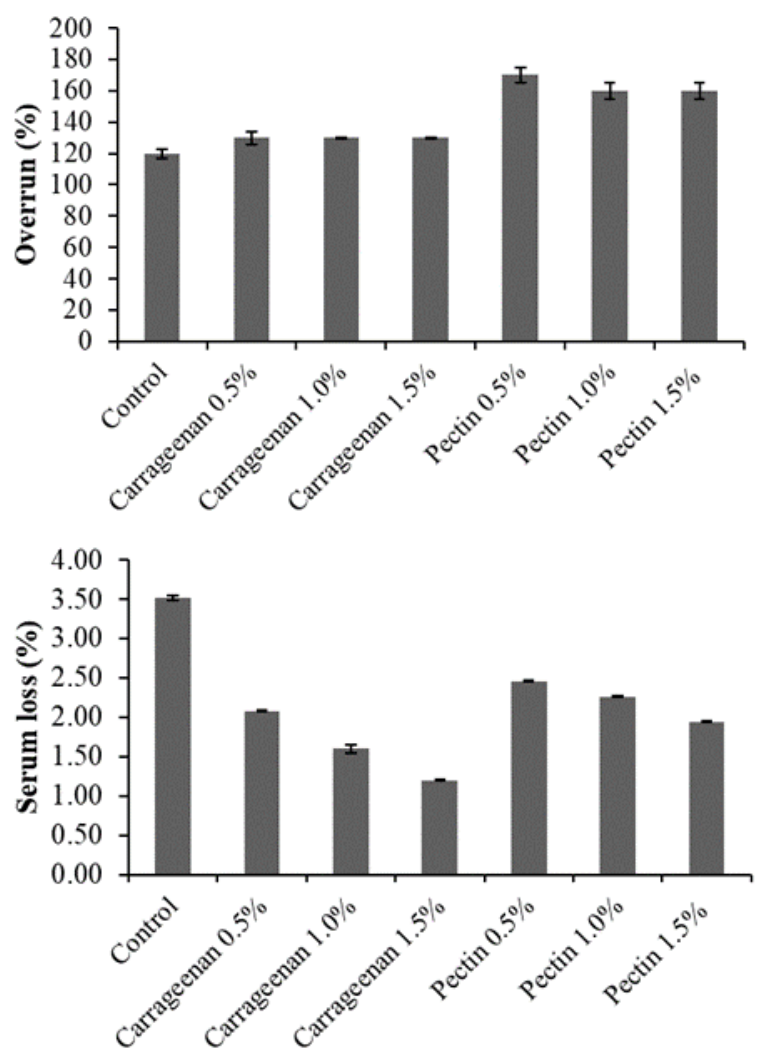

Figure 1. Overrun and serum loss of the whipped cream samples

In terms of serum loss, it can be observed that the addition of gums plays a significant role in the reduction of serum loss. Mostly, foam is more stable at high viscosity because increasing the viscosity of the aqueous phase, leads to the creation of a network structure in the bulk phase that would keep the interfacial wall from easily breaking, which causes improved foam stability (Salahi et al., 2015). In this study, whipped creams with added hydrocolloids showed less serum loss indicating their high stability when compared to the control. The higher the hydrocolloid level the better foam stability (less serum loss). Hydrocolloids have been reported to affect foam stability, depending on the types and concentrations of the hydrocolloids. It has been reported that some hydrocolloids can either increase or decrease foam stability as the concentration increased. Foam stability is the key step in studying foam systems. Foam stability is influenced by the physical and rheological properties of the interface and the continuous phase. Thickness of the interface, bubble size distribution, interface permeability and surface tension are effective on foam stability (Farahmandfar et al., 2017).

\subsection{Lipid digestion}

Images of the emulsions in the test tubes prepared from carrageenan and pectin added whipping creams before and after passing through the digestion model $(\mathrm{pH}$ $7.0 ; 2.0 ; 5.3 ; 7.5$ ) are shown in Figure 2 . Please note that only the control and $1.5 \%$ samples of both hydrocolloids are shown. The others provided similar patterns so the images are not shown here. Besides, the creaming stability values, as determined by measuring the percentage of the height of the cream layer formed at the top of the emulsion after $24 \mathrm{hrs}$ storage at $25^{\circ} \mathrm{C}$, are shown in Table 2.

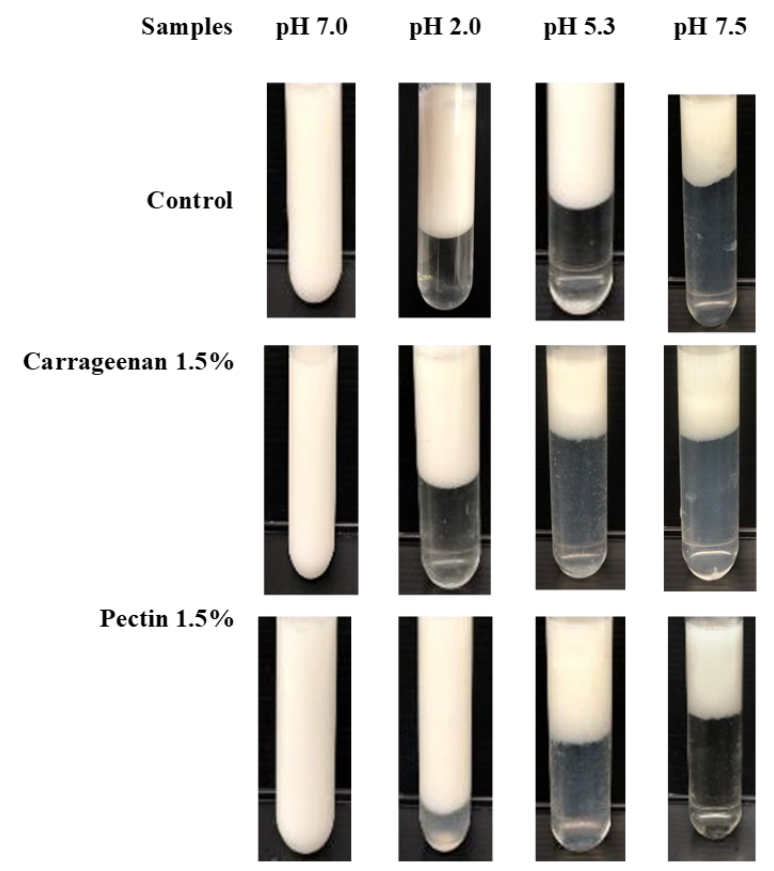

Figure 2. Images of the emulsions with added pectin and carrageenan before and after passing through the digestion model 
Table 2. Creaming stability as determined by measuring the percentage of the height of the cream layer

\begin{tabular}{lcccc}
\hline \multirow{2}{*}{ Samples } & \multicolumn{4}{c}{ Creaming stability (\%) } \\
\cline { 2 - 5 } & $\mathrm{pH} \mathrm{7.0}$ & $\mathrm{pH} \mathrm{2.0}$ & $\mathrm{pH} \mathrm{5.3}$ & $\mathrm{pH} \mathrm{7.5}$ \\
\hline Control & - & $79.12 \pm 0.04^{\mathrm{a}}$ & $57.50 \pm 0.12^{\mathrm{a}}$ & $42.52 \pm 0.12^{\mathrm{a}}$ \\
Carrageenan 0.5\% & - & $72.58 \pm 0.11^{\mathrm{e}}$ & $57.53 \pm 0.12^{\mathrm{a}}$ & $35.42 \pm 0.08^{\mathrm{c}}$ \\
Carrageenan 1.0\% & - & $70.00 \pm 0.12^{\mathrm{f}}$ & $55.75 \pm 0.14^{\mathrm{b}}$ & $27.55 \pm 0.12^{\mathrm{e}}$ \\
Carrageenan 1.5\% & - & $52.08 \pm 0.15^{\mathrm{g}}$ & $33.33 \pm 0.29^{\mathrm{f}}$ & $17.92 \pm 0.27^{\mathrm{f}}$ \\
Pectin 0.5\% & - & $77.52 \pm 00.08^{\mathrm{b}}$ & $47.53 \pm 0.10^{\mathrm{d}}$ & $35.00 \pm 0.02^{\mathrm{c}}$ \\
Pectin 1.0\% & - & $76.43 \pm 0.13^{\mathrm{c}}$ & $45.24 \pm 0.06^{\mathrm{e}}$ & $32.12 \pm 0.10^{\mathrm{d}}$ \\
Pectin 1.5\% & - & $75.05 \pm 0.15^{\mathrm{d}}$ & $50.23 \pm 0.12^{\mathrm{c}}$ & $40.10 \pm 0.10^{\mathrm{b}}$ \\
\hline
\end{tabular}

Values are mean \pm standard deviation (triplicate). Means with different superscript letters within a column are significantly different $(\mathrm{p} \leq 0.05)$.

In addition, light microscopic images showing lipid droplets of the emulsions with pectin and carrageenan after passing through each step of the digestion model are shown in Figure 3.

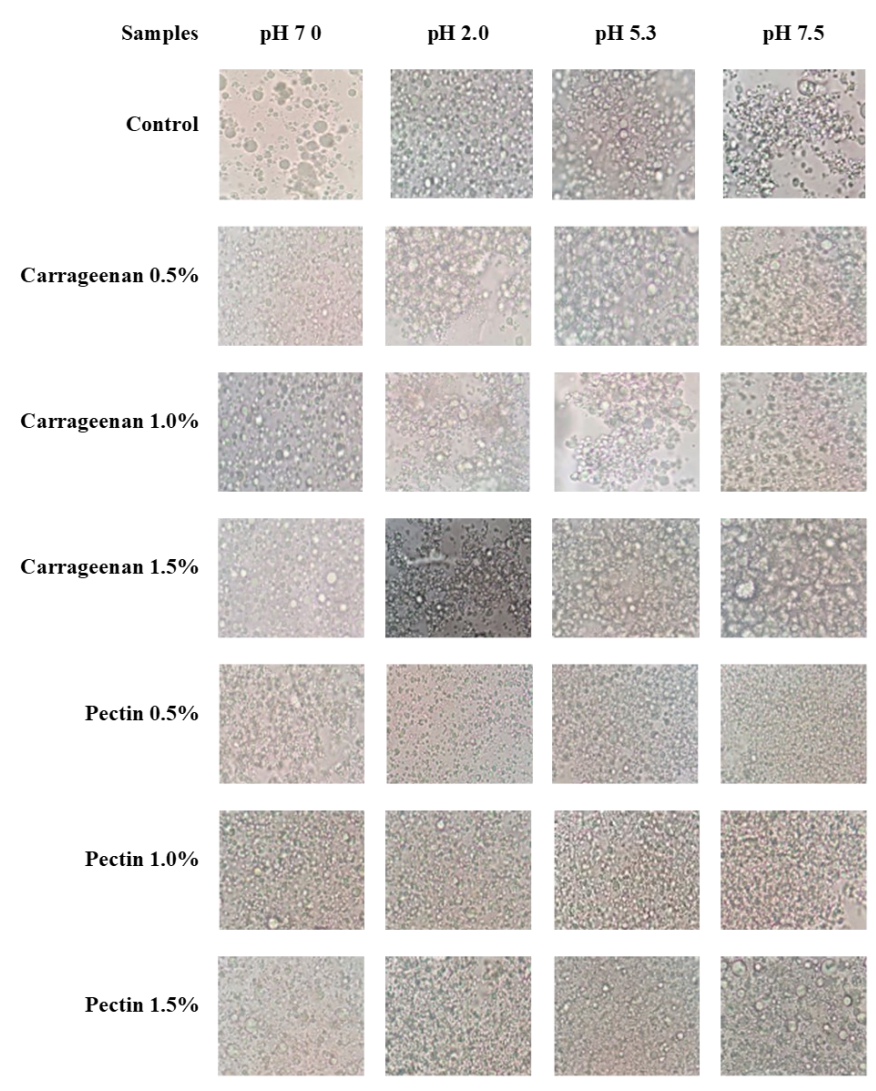

Figure 3. Light microscopic images (200x) of the emulsions with added pectin and carrageenan before and after passing through the digestion model

It was found that carrageenan and pectin provided similar patterns of results. In the presence of both hydrocolloids, the emulsions exhibited appreciable droplet flocculation and/or coalescence when exposed to $\mathrm{pH}$ changes through the digestion model. This resulted in creaming and phase separation of the emulsions (Figure 2). Flocculation of the emulsions occurred from $\mathrm{pH} 2.0$ and the creaming stability values, as shown in Table 2 , decreased as the digestion passed from $\mathrm{pH} 2.0$ to 5.3 and the final $\mathrm{pH}$ of 7.5. From optical microscopy images, it was found that oil droplets became flocculated and/or coalescent depending on the types of hydrocolloids and $\mathrm{pH}$ changes during the digestion model. Moreover, the increase in the net negative charge on the oil droplets (refers to Table 1) in both pectin and carrageenan added samples would increase the electrostatic repulsion between the oil droplets and thus reduce the tendency of droplet aggregation to occur (Mun et al., 2007). Coalescence was obvious in the control samples as evidenced by large individual oil droplets. While whipping cream emulsions with the presence of pectin appeared to be more prone to droplet flocculation than coalescence as many clustered droplets were observed rather than large individual droplets (Figure 3). On the other hand, emulsions with carrageenan were highly prone to droplet coalescence with evidence of large individual oil droplets being observed (Figure 3). The origin of droplet aggregation in the emulsions during lipase digestion has been reported to depend on the ability of lipase to come into contact with the emulsified lipid as well as on the composition and properties of the interfacial layers surrounding the lipid droplets. Thus, the stability of the emulsions to droplet aggregation during digestion is strongly dependent on the emulsifiers or hydrocolloids used (Mun et al., 2007). The released FFAs which are related to the rate of lipid digestion are shown in Table 3.

Table 3. The released FFAs of the whipped cream samples after passing through the digestion model

\begin{tabular}{lc}
\hline \multicolumn{1}{c}{ Samples } & FFAs $(\%$ as oleic acid $)$ \\
\hline Control & $14.10 \pm 1.33^{\mathrm{a}}$ \\
Carrageenan $0.5 \%$ & $7.07 \pm 0.53^{\mathrm{b}}$ \\
Carrageenan $1.0 \%$ & $4.75 \pm 0.84^{\mathrm{c}}$ \\
Carrageenan $1.5 \%$ & $2.48 \pm 0.88^{\mathrm{d}}$ \\
Pectin $0.5 \%$ & $8.23 \pm 0.37^{\mathrm{b}}$ \\
Pectin $1.0 \%$ & $7.18 \pm 0.52^{\mathrm{c}}$ \\
Pectin $1.5 \%$ & $5.94 \pm 0.39^{\mathrm{d}}$ \\
\hline
\end{tabular}

Values are mean \pm standard deviation (triplicate). Means with different superscript letters within a column are significantly different $(\mathrm{p} \leq 0.05)$. 
Both carrageenan and pectin showed a potential inhibitor of lipid digestion, resulting in the lower amount of released FFAs (Table 3) when compared to the control sample. Comparing both hydrocolloids, carrageenan provided slightly lower FFAs than those of pectin. This suggested that droplet coalescence (carrageenan) may provide better protection against lipase hydrolysis than droplet flocculation (pectin).

It should be emphasized that lipid digestion is an interfacial-mediated process, which means that the rate of digestion is controlled by the ability of lipase to bind to emulsion interfaces. This process is mainly controlled by droplet size and interfacial characteristics (e.g. initial composition, thickness, and charge) surrounding the lipid droplets. Different hydrocolloids may influence the digestion of emulsified lipids by means of various mechanisms e.g. binding to various intestinal components, altering the aggregation state of the oil droplets, forming protective coatings around lipid droplets, or increasing the macroscopic viscosity of gastrointestinal fluids (McClements et al., 2008; Qin et al., 2016; Borreani et al., 2019). In addition, it can be concluded that lipid digestion may potentially be influenced by oil droplet size which influences the surface area available for lipase adsorption, macroscopic viscosity of the systems which affects mass transport, and the nature of the hydrocolloids/emulsifiers used in emulsions which influences interfacial phenomena (Borreani et al., 2019).

In this study, both hydrocolloids at the studied conditions altered lipid digestion in whipped cream samples as evidence by droplet aggregations, either coalescence or flocculation patterns, as well as the reduction in released FFAs when compared to the control. Carrageenan seemed to be more effective in reducing the rate of lipid digestion than pectin, providing the lower FFAs.

In accordance with the possible impact of droplet size on lipid digestion, the emulsions with pectin and carrageenan exhibited a smaller droplet size than that of the control (refers to Table 1). Therefore, they should be more rapid in the digestion rate. However, this study found that the droplet size or volume-surface average diameter of the emulsions with pectin and carrageenan inversely correlated with the digestion rate or released FFAs. This phenomenon has been studied and explained earlier. FFAs released from the emulsions were found to show no correlation to the initial specific surface area of the emulsions, nor to the values of the surface area at the end of gastric digestion. They concluded that the structural characteristics of the interfacial surfaces may be a key factor in explaining the differences observed in
FFA release (Bellesi et al., 2016). It has also been hypothesized that factors other than oil droplet size may have a greater impact on the rate and extent of lipid digestion (Borreani et al., 2019).

\section{Conclusion}

Whipping creams are high in lipids. Hydrocolloids could be used in whipping creams, providing key benefits for not only as emulsifiers/stabilizers but also functional dietary fibers that retarded lipid digestion rate. In this study, pectin and carrageenan were found to improve the foaming properties of whipping cream, providing better overrun and serum loss. They also reduced the rate of lipid digestion as evidenced by lipid droplet aggregations and the decrease in released FFAs after the digestion process. The results from this study indicate that the rate and extent of lipid digestion may be controlled by adding certain types of polysaccharides, which may be useful for the rational design of functional foods and beverages. The choice of particle size and emulsifiers/hydrocolloids are therefore major factors to take into account when designing food to reduce lipid digestion.

\section{Conflict of Interest}

The authors declare no conflict of interest.

\section{Acknowledgments}

This study was financially supported by the Thailand Science Research and Innovation, formerly known as the Thailand Research Fund (TRF-RRI Grant No. MSD61I0012). The cooperation from the industrial partner is greatly acknowledged.

\section{References}

Allen, K.E., Dickinson, E. and Murray, B. (2006). Acidified sodium caseinate emulsion foams containing liquid fat: A comparison with whipped cream. LWT - Food Science and Technology, 39(3), 225-234. https://doi.org/10.1016/j.lwt.2005.02.004

Bellesi, F.A., Martinez, M.J., Pizones Ruiz-Henestrosa, V.M. and Pilosof, A.M.R. (2016). Comparative behavior of protein or polysaccharide stabilized emulsion under in vitro gastrointestinal conditions. Food Hydrocolloids, 52, 47-56. https:// doi.org/10.1016/j.foodhyd.2015.06.007

Beysseriat, M., Decker, E.A. and McClements, D.J. (2006). Preliminary study of the influence of dietary fiber on the properties of oil-in-water emulsions passing through an in vitro human digestion model. Food Hydrocolloids, 20(6), 800-809. https:// 
doi.org/10.1016/j.foodhyd.2005.08.001

Borreani, J., Leonardi, C., Moraga, G., Quiles, A. and Hernando, I. (2019). How do different types of emulsifiers/stabilizers affect the in vitro intestinal digestion of $\mathrm{O} / \mathrm{W}$ emulsions? Food Biophysics, 14, 313-325. https://doi.org/10.1007/s11483-019-095822

Camacho, M.M., Martinez-Navarrete, N. and Chiralt, A. (2005). Rheological characterization of experimental dairy creams formulated with locust bean gum (LBG) and $\lambda$-carrageenan combinations. International Dairy Journal, 15(3), 243-248. https:// doi.org/10.1016/j.idairyj.2004.07.008

Camacho, M.M., Martínez-Navarrete, N. and Chiralt, A. (1998). Influence of locust bean gum/ $\lambda$-carrageenan mixtures on whipping and mechanical properties and stability of dairy creams. Food Research International, 31(9), 653-658. https:// doi.org/10.1016/S0963-9969(99)00041-1

Camacho, M.M., Martínez-Navarrete, N. and Chiralt, A. (2001). Stability of whipped dairy creams containing locust bean gum $/ \lambda$-carrageenan mixtures during freezing-thawing processes. Food Research International, 34(10), 887-894. https:// doi.org/10.1016/S0963-9969(01)00113-2

Chang, Y. and McClements, D.J. (2016). Influence of emulsifier type on the in vitro digestion of fish oil-in -water emulsions in the presence of an anionic marine polysaccharide (fucoidan): Caseinate, whey protein, lecithin, or Tween 80. Food Hydrocolloids, 61, 92-101. https://doi.org/10.1016/ j.foodhyd.2016.04.047

Dalgleish, D.G. and Morris, E.R. (1988). Interactions between carrageenans and casein micelles: electrophoretic and hydrodynamic properties of the particles. Food Hydrocolloids, 2(4), 311-320. https://doi.org/10.1016/S0268-005X(88)80028-6

Dewettinck, K., Rombaut, R., Thienpont, N., Le, T.T., Messens, K. and Van Camp, J. (2008). Nutritional and technological aspects of milk fat globule membrane material. International Dairy Journal, 18 (5), 436-457. https://doi.org/10.1016/ j.idairyj.2007.10.014

Farahmandfar, R., Asnaashari, M., Salahi, M.R. and Khosravi Rad, T. (2017). Effects of basil seed gum, cress seed gum and quince seed gum on the physical, textural and rheological properties of whipped cream. International Journal of Biological Macromolecules, 98, 820-828. https:// doi.org/10.1016/j.ijbiomac.2017.02.046

Farahmandfar, R., Asnaashari, M., Taheri, A. and Rad, T.K. (2019). Flow behavior, viscoelastic, textural and foaming characterization of whipped cream: Influence of Lallemantia royleana seed, Salvia macrosiphon seed and carrageenan gums. International Journal of Biological Macromolecules, 121, 609-615. https://doi.org/10.1016/ j.ijbiomac.2018.09.163

Hemar, Y., Tamehana, M., Munro, P.A. and Singh, H. (2001). Influence of xanthan gum on the formation and stability of sodium caseinate oil-in-water emulsions. Food Hydrocolloids, 15(4-6), 513-519. https://doi.org/10.1016/S0268-005X(01)00075-3

Hotrum, N.E., Stuart, M.A.C., van Vliet, T., Avino, S.F. and van Aken, G.A. (2005). Elucidating the relationship between the spreading coefficient, surface-mediated partial coalescence and the whipping time of artificial cream. Colloids and Surfaces A: Physicochemical and Engineering Aspects, 260(1-3), 71-78. https://doi.org/10.1016/ j.colsurfa.2005.03.004

Jakubczyk, E. and Niranjan, K. (2006). Transient development of whipped cream properties. Journal of Food Engineering, 77(1), 79-83. https:// doi.org/10.1016/j.jfoodeng.2005.06.046

Klinkesorn, U. and McClements, D.J. (2009). Influence of chitosan on stability and lipase digestibility of lecithin-stabilized tuna oil-in-water emulsions. Food Chemistry, 114(4), 1308-1315. https:// doi.org/10.1016/j.foodchem.2008.11.012

McClements, D.J., Decker, E.A., Park, Y. and Weiss, J. (2008). Designing food structure to control stability, digestion, release and absorption of lipophilic food components. Food Biophysics, 3, 219-228. https:// doi.org/10.1007/s11483-008-9070-y

Mun, S., Decker, E.A. and McClements, D.J. (2007). Influence of emulsifier type on in vitro digestibility of lipid droplets by pancreatic lipase. Food Research International, 40(6), 770-781. https:// doi.org/10.1016/j.foodres.2007.01.007

Nguyen, V., Duong, C.T.M. and Vu, V. (2015). Effect of thermal treatment on physical properties and stability of whipping and whipped cream. Journal of Food Engineering, 163, 32-36. https://doi.org/10.1016/ j.jfoodeng.2015.04.026

Pérez, O.E., Carrera-Sánchez, C., Rodríguez-Patino, J.M. and Pilosof, A.M.R. (2007). Adsorption dynamics and surface activity at equilibrium of whey proteins and hydroxypropyl-methyl-cellulose mixtures at the air-water interface. Food Hydrocolloids, 21(5-6), 794-803. https://doi.org/10.1016/ j.foodhyd.2006.11.013

Qin, D., Yang, X., Gao, S., Yao, J. and McClements, D.J. (2016). Influence of hydrocolloids (dietary 
fibers) on lipid digestion of protein-stabilized emulsions: Comparison of neutral, anionic, and cationic polysaccharides. Journal of Food Science, 81(7), C1636-C1645. https://doi.org/10.1111/17503841.13361

Qin, D., Yang, X., Gao, S., Yao, J. and McClements, D.J. (2017). Influence of dietary fibers on lipid digestion: Comparison of single-stage and multiplestage gastrointestinal models. Food Hydrocolloids, 69, 382-392. https://doi.org/10.1016/ j.foodhyd.2017.03.004

Salahi, M.R., Mohebbi, M. and Taghizadeh, M. (2015). Foam-mat drying of cantaloupe (Cucumis melo): Optimization of foaming parameters and investigating drying characteristics. Journal of Food Processing and Preservation, 39(6), 1798-1808. https://doi.org/10.1111/jfpp.12414

Scurlock, P.G. (1986). Production of cream from ultrafiltered milk. Journal of Dairy Research, 53(3), 431-438.

https://doi.org/10.1017/ S0022029900025048

Srikaeo, K. and Pradit, M. (2011). Simple techniques to increase the production yield and enhance the quality of organic rice bran oils. Journal of Oleo Science, 60 (Issue 1), 1-5. https://doi.org/10.5650/jos.60.1

Srikaeo, K. and Singchai, J. (2016). Effects of konjac glucomannan and resistant starch on in vitro lipid digestion of non-dairy creamers. International Food Research Journal, 23(4), 1403-1408.

Thanasukarn, P., Pongsawatmanit, R. and McClements, D.J. (2004). Influence of emulsifier type on freezethaw stability of hydrogenated palm oil-in-water emulsions. Food Hydrocolloids, 18(6), 1033-1043. https://doi.org/10.1016/j.foodhyd.2004.04.010

Torcello-Gómez, A., Jódar-Reyes, A.B., MaldonadoValderrama, J. and Martín-Rodríguez, A. (2012). Effect of emulsifier type against the action of bile salts at oil-water interfaces. Food Research International, 48(1), 140-147. https:// doi.org/10.1016/j.foodres.2012.03.007

Viebke, C., Al-Assaf, S. and Phillips, G.O. (2014). Food hydrocolloids and health claims. Bioactive Carbohydrates and Dietary Fibre, 4(2), 101-114. https://doi.org/10.1016/j.bcdf.2014.06.006

Wollenweber, C., Makievski, A.V., Miller, R. and Daniels, R. (2000). Adsorption of hydroxypropyl methylcellulose at the liquid/liquid interface and the effect on emulsion stability. Colloids and Surfaces A: Physicochemical and Engineering Aspects, 172(1 -3), 91-101. https://doi.org/10.1016/S0927-7757(00) 00569-0

Yao, X., Zhang, W., Nie, K., Gao, Z., Fang, Y.,
Nishinari, K., Phillips, G.O. and Jiang, F. (2016). Effect of gum arabic, gum ghatti and sugar beet pectin as interfacial layer on lipid digestibility in oilin-water emulsions. Food Biophysics, 11, 292-301. https://doi.org/10.1007/s11483-016-9441-8

Zhao, Q., Zhao, M., Li, J., Yang, B., Su, G., Cui, C. and Jiang, Y. (2009). Effect of hydroxypropyl methylcellulose on the textural and whipping properties of whipped cream. Food Hydrocolloids, 23(8), 2168-2173. https://doi.org/10.1016/ j.foodhyd.2009.04.007

Zhao, Q., Zhao, M., Yang, B. and Cui, C. (2009). Effect of xanthan gum on the physical properties and textural characteristics of whipped cream. Food Chemistry, 116(3), 624-628. https://doi.org/10.1016/ j.foodchem.2009.02.079 